\title{
Intensity of Home-Based Telework and Work Engagement During the COVID-19 Pandemic
}

\author{
Tomohisa Nagata, MD, PhD, Masako Nagata, MD, PhD, Kazunori Ikegami, MD, PhD, Ayako Hino, MD, PhD, \\ Seiichiro Tateishi, MD, PhD, Mayumi Tsuji, MD, PhD, Shinya Matsuda, MD, PhD, \\ Yoshihisa Fujino, MD, MPH, PhD, and Koji Mori, MD, PhD, for the CORoNaWork project
}

\begin{abstract}
Objective: The present study examined the relationship between the intensity of home-based telework and work engagement. Methods: This crosssectional study using a self-administrated questionnaire survey was conducted from December 22 to 25, 2020, in Japan. The subjects were asked single-item questions about the intensity of telework and three-item questions about work engagement using the Utrecht Work Engagement Scale. Coefficients were estimated using a multilevel regression model nested by the prefecture of residence and adjusted for covariates. Results: Highintensity (4 or more days per week) telework was not associated with high work engagement for men or women. In contrast, low and moderate intensity (3 days per week to once per month) were associated with high work engagement. The results were consistent when stratified by sex.
\end{abstract}

From the Department of Occupational Health Practice and Management, Institute of Industrial Ecological Sciences, University of Occupational and Environmental Health, Japan (Dr Nagata, Dr Nagata, Dr Mori), Department of Work Systems and Health, Institute of Industrial Ecological Sciences, University of Occupational and Environmental Health, Japan (Dr Ikegami), Department of Mental Health, Institute of Industrial Ecological Sciences, University of Occupational and Environmental Health, Japan (Dr Hino), Department of Occupational Medicine, School of Medicine, University of Occupationa and Environmental Health, Japan (Dr Tateishi), Department of Environmental Health, School of Medicine, University of Occupational and Environmental Health, Japan (Dr Tsuji), Department of Public Health, School of Medicine, University of Occupational and Environmental Health, Japan (Dr Matsuda), Department of Environmental Epidemiology, Institute of Industrial Ecological Sciences, University of Occupational and Environmental Health, Japan (Dr Fujino).

Funding: This study was funded by a research grant from the University of Occupational and Environmental Health, Japan; a general incorporated foundation (Anshin Zaidan) for the development of educational materials on mental health measures for managers at small-sized enterprises; Health, Labour and Welfare Sciences Research Grants: Comprehensive Research for Women's Healthcare (H30-josei-ippan-002) and Research for the establishment of an occupational health system in times of disaster (H30-roudouippan-007); consigned research foundation (the Collabo-health Study Group); and scholarship donations from Chugai Pharmaceutical Co., Ltd.

T. Nagata, M. Nagata, Ikegami, Hino, Tateishi, Tsuji, Matsuda, Fujino, and Mori, for the CORoNaWork project have no relationships/conditions/circumstances that present potential conflict of interest.

The JOEM editorial board and planners have no financial interest related to this research

Clinical significance: This study revealed that a reasonable intensity of telework may have beneficial effects on work engagement. A reasonable intensity is defined as low (once per week to once per month) or moderate-intensity ( 2 to 3 days per week) for both men and women.

Address correspondence to: Tomohisa Nagata, MD, PhD, Department of Occupational Health Practice and Management, Institute of Industrial Ecological Sciences, University of Occupational and Environmental Health, 1-1 Iseigaoka, Yahatanishi-ku, Kitakyushu 807-8555, Japan (tomohisa@med.uoeh-u. ac.jp).

Copyright (C) 2021 The Author(s). Published by Wolters Kluwer Health, Inc. on behalf of the American College of Occupational and Environmental Medicine. This is an open access article distributed under the terms of the Creative Commons Attribution-Non Commercial-No Derivatives License 4.0 (CCBY-NC-ND), where it is permissible to download and share the work provided it is properly cited. The work cannot be changed in any way or used commercially without permission from the journal.

DOI: 10.1097/JOM.0000000000002299

\section{Learning Objectives}

- Review previous findings on the mental health effects of home-based telework.

- Summarize the new findings on the association between intensity of telework and work engagement in a Japanese survey sample.

- Discuss the implications for the appropriate level of telework intensity to promote work engagement.

Conclusions: Reasonable-intensity telework may have beneficial effects on work engagement.

Keywords: COVID-19, home-based telework, Japan, telecommuting, work engagement

$\mathrm{n}$ response to the economic and social strain induced by the

COVID-19 pandemic, the Japanese government officially declared a state of emergency on April 8, 2020, in an effort to prevent the collapse of medical services. ${ }^{1}$ While the declaration was initially limited to seven prefectures, it was expanded to include the entire country on April 16, 2020. ${ }^{2}$ To limit the spread of COVID-19, many companies have made major changes to employees' working style, and the frequency of opportunities to engage in home-based telework has dramatically increased. Indeed, in a November 2020 survey of approximately 20,000 people, the national average telework implementation rate among full-time employees in Japan was $24.7 \%$.

A review paper on the mental health effects of home-based telework showed that telework has increased isolation, depression, stress, and overwork. However, this result is inconsistent with the findings of previous studies. ${ }^{4}$ One study found that employees who telecommuted eight or fewer hours per month were significantly less likely than non-telecommuters to experience depression. ${ }^{5}$ As background to these results, the authors pointed out that the characteristics and conditions of telework (workplace support, autonomy, etc) are more important than whether one is simply a teleworker or not. ${ }^{6}$ Consideration should be given to not only the negative influences on mental health but also the positive influences of this approach to work. Work engagement, one such positive influence, is a concept characterized by vigor, dedication, and absorption. ${ }^{7}$ In a cross-sectional study describing the relationship between the extent of telecommuting and work engagement, the working environment, such as social support from colleagues, was found to influence work engagement, although no direct influence of telecommuting on engagement was noted. ${ }^{6}$

Many workers were forced into telework without any preparation time due to the relatively sudden appearance of the COVID19 pandemic. ${ }^{8,9}$ Before the pandemic, telework was often available to individual employees as an option, ${ }^{10}$ with a high degree of flexibility afforded them in terms of where and when they could work. However, the working environment and conditions during the 
pandemic are markedly different from the norm, as workers are often deprived of the choice to telework or not. Telework under a pandemic can eliminate the risk of infection in the workplace, so workers can work with a sense of security, which may enhance the work engagement of teleworkers. However, the question of how home-based telework affects work engagement under a pandemic is unclear.

The present study examined the relationship between the intensity of home-based telework and work engagement adjusted for the work environment, such as workplace support and decision latitude. We also analyzed the results by sex, an approach adopted by many previous studies, ${ }^{11}$ as men and women often perform different roles in the household, which is likely to affect the results. One study found less fatigue and stress in men who regularly worked from home than in those who did not; in contrast, less stress but greater fatigue was noted in women who worked from home than in those who did not. ${ }^{12}$ Telework was also shown to be associated with greater stress as well as happiness in male workers, although no such effect was found in female workers. ${ }^{13}$ To the best of our knowledge, however, no studies have examined the relationship between telework and work engagement by sex.

\section{METHODS}

A research group from the University of Occupational and Environmental Health, Japan, conducted a prospective cohort study, known as the Collaborative Online Research on Novel-coronavirus and Work study (CORoNaWork study), as a self-administrated questionnaire survey through the internet survey company Cross Marketing Inc. (Tokyo, Japan). During the baseline survey, conducted December 22 to 25, 2020, Japan was in the midst of its third wave of the pandemic, at which point the number of COVID-19 infections and deaths was markedly higher than in the first and second waves; the country was thus on high alert.

A portion of the baseline survey from the CORoNaWork study was used to conduct the present cross-sectional study. The study protocol, including the sampling plan and subject recruitment procedure, has been previously reported in detail. ${ }^{14}$ Participants were aged 20 to 65 years and working at the time of the baseline survey ( $n=33,087$ total). Participants in the CORoNaWork study were stratified by cluster sampling according to gender, age, and region. After excluding 6051 initial subjects who provided invalid responses, we ultimately included 27,036 in the database. We analyzed the 19,659 workers remaining after further excluding self-employed workers (2709), workers in small/home offices (2721), and agriculture, forestry, and fishing workers (1947) to meet the research purposes.

The present study was approved by the Ethics Committee of the University of Occupational and Environmental Health, Japan.

\section{Measures}

\section{Assessment of Intensity of Home-Based Telework}

We asked subjects, "Do you work at home? Please choose the answer that is closest to your current situation," and respondents chose one of the following five options: 4 days a week or more; 2 to 3 days a week; 1 day a week; More than once a month but less than once a week; and Never. Participants were divided into four groups by intensity of telework: high intensity for telework $\geq 4$ days/week, moderate intensity for telework 2-3 days/week, low intensity for telework once a week to once a month, and no telework for those without teleworking.

\section{Assessment of Work Engagement}

The three-item Japanese version of the Utrecht Work Engagement Scale (UWES-3) was used to assess work engagement. ${ }^{15,16}$ The UWES- 9 has previously been translated into Japanese, and the
Japanese version was found to have acceptable internal consistency and reliability as well as a factor and construct validity. ${ }^{15}$ The items of UWES-3 were selected from among those included in the UWES9. The UWES-3 has been validated in five countries, including Japan $^{16}$ and includes measures of vigor (one item), dedication (one item), and absorption (one item), with each item measured on a seven-point response scale ranging from 0 (never) to 6 (always/ every day). Overall scores on the UWES-3 (range: 0-6) are calculated by averaging the individual item scores. Cronbach $\alpha$ coefficient for the total UWES-3 score in this study was 0.92 .

\section{Assessment of Covariates}

Covariates included demographic, socioeconomic factors, occupation and industry, psychological demands, decision latitude, and workplace support. Age was expressed as a continuous variable. Education was classified into five categories: junior high school, high school, junior college or technical school, university, and graduate school. Yearly household income was classified into four categories: $<2.50$ million Japanese yen (JPY); 2.50-3.75 million JPY; 3.75-5.25 million JPY; and >5.25 million JPY. Marital status was classified into three categories: married; divorced or widowed; and never married. The presence of family living together was classified into two categories: present and absent. In this survey, participants chose 1 of 10 options for their occupation: general employee; manager; executive manager; public employee, faculty member, or non-profit organization employee; temporary/contract employee; self-employed; SOHO; agriculture, forestry, or fishing; professional occupations (lawyer, tax accountant, medical-related, etc); and other occupations. Three of these categories were excluded from this study, as mentioned above, so the occupations were ultimately classified into seven categories. The participants chose 1 of 22 options for their working industry: energy, materials, industrial machinery; food; beverages/tobacco products; pharmaceuticals/medical supplies; cosmetics/toiletries/sanitary products; fashion and accessories; precision machinery and office supplies; home appliances/audiovisual equipment; automobiles and transportation equipment; household goods; hobby/sporting goods; real estate and housing equipment; information and communication; distribution and retail; finance/insurance; transportation and leisure; restaurant and other services; public offices and organizations; education, medical services, religion; mass media; market research; and others.

Work-related stress was assessed by the 22-item Japanese version of the Job Content Questionnaire. ${ }^{17,18}$ The Job Content Questionnaire comprises a five-item psychological demands scale (response range 12-48), a nine-item decision latitude scale (response range 24-96), and an eight-item workplace support scale (response range $8-32$ ) created by summing supervisor support and co-worker support. Each item was measured on a four-point Likert type scale ranging from 1 (strongly disagree) to 4 (strongly agree). A higher score for each question means high psychological demands, high decision latitude, and high workplace support. In previous studies concerning the relationship between telework and work engagement, a theoretical model with three factors mediating the relationship between the two was developed. ${ }^{6}$ In the present study with the same target population, we also found that telework was related to three factors: psychological demands, decision latitude, and workplace support. ${ }^{19}$

In addition, the prefecture of residence was used as a community-level variable.

\section{Statistical Analyses}

Multilevel regression analyses were used to examine the association between the intensity of telework and work engagement. We analyzed nested by the prefecture of residence because the rate of telework implementation differs by region. The difference in the 
rate of telework implementation is attributed to the different conditions of commuting by public transportation between urban and rural cities, and the different status of the COVID-19 infection. The unstandardized coefficients and standard errors were estimated using multilevel regression analyses nested by the prefecture of residence and adjusted for sex and age (Model 1). We then additionally adjusted for income, marriage, and the presence of family living together (Model 2), along with occupation and industry (Model 3), and psychological demand, decision latitude, and workplace support (Model 4). We also calculated the prefecture-level intra-class correlation coefficient in Model 4. We did not adjust for education, as adjusting for education would constitute over-adjustment. In addition, we performed sex-stratified analyses in the same manner.

The level of significance was set at 0.05 (two-tailed). A trend test was conducted by treating the surveyed telework as a continuous variable on a five-point scale (one to five points) in order of decreasing frequency and performing the analysis in the same manner. All analyses were performed using Stata 16SE (StataCorp LLC, College Station, TX, USA).

\section{RESULTS}

The mean age was higher for men than for women. Men also had higher educational attainment and yearly household income than women. The percentage of married people was higher among men than women. Psychological demands were higher in women, whereas decision latitude was higher in men. No marked difference in workplace support by sex was noted. The proportion of telework was higher for men $(21 \%)$ than for women $(15 \%)$ (Table 1$)$.

Among all subjects (men and women), all intensity categories of telework were significantly associated with work engagement adjusted for age and sex (Model 1). After adjusting for demographics, including socioeconomic factors, occupation, and industry (Model 3), all intensity categories of telework were also associated with work engagement (Table 2). This association remained significant after additionally adjusting for psychological demands, decision latitude, and workplace support for low- and moderate-intensity telework, although not for high-intensity telework (Model 4). The prefecture-level intra-class correlation coefficient was 0.0009 (95\% confidential interval (CI): $0.0002-$ $0.0036)$ in Model 4.

In the sex-stratified analysis, the prefecture-level intra-class correlation coefficient was 0.0020 (95\% CI: $0.0006-0.0061)$ for men and 0.0004 (95\% CI: 0.0000-0.0010) for women. After adjusting for demographic factors, including socioeconomic factors and occupation and industry (Model 3), all intensity categories of telework were significantly associated with work engagement. This association remained significant after additionally adjusting for psychological demands, decision latitude, and workplace support for low- and moderate-intensity telework, although not for highintensity telework for both sexes (Model 4). The prefecture-level intra-class correlation coefficient was 0.0020 (95\% CI: $0.0006-$ 0.0061 ) for men and 0.0004 (95\% CI: 0.0000-0.0010) for women in Model 4.

\section{DISCUSSION}

The present study revealed an association between homebased telework and work engagement, although the trend differed depending on the intensity of telework. High-intensity telework ( $\geq 4$ days per week) was not associated with high work engagement, while low-intensity telework (once per month to once per week) and moderate-intensity telework (2-3 days per week) had high work engagement for both men and women.

A previous study revealed an indirect relationship between the extent of telecommuting and work engagement via social support, but no direct relationship between telecommuting and work engagement was noted. ${ }^{6}$ The authors analyzed the relationship between work engagement and telecommuting using seven levels of intensity in a week as a continuous variable. The present study still had the relationship between the intensity of home-based telework and work engagement adjusted for the work environment, such as workplace support and decision latitude. Telework may have enhanced work engagements by lowering the risk of infection. We classified telework into categories based on intensity and conducted analyses by each category, resulting in the demonstration that telework with low-to-moderate intensity was associated with the possibility of increasing work engagement. If the only factor that increases work engagement is a reduction in the risk of infection, then the higher the intensity of telework, the higher the work engagement should be. It is difficult to explain this result in terms of infection risk alone. Telework with an appropriate frequency may increase work engagement. Autonomy has been shown to play an important role in the relationship between telecommunication intensity and job satisfaction. ${ }^{10}$ The key to making telework function more productively is to adopt a management style suitable to telework based on trust and management between supervisor and colleagues and among individual colleagues. ${ }^{20}$ If workers are able to work autonomously and the company is able to provide a suitable working environment for them, workers engaged in high-intensity telework may still be able to maintain high work engagement. A previous study in Japan revealed an increase in labor productivity with a suitable number of teleworking hours; however, when teleworking hours were too long, labor productivity was reduced, ${ }^{13}$ suggesting that telework may have negative health effects if overloaded.

Our analysis also showed similar results to a previous study ${ }^{6}$ when the workplace environment factors of psychological demands, decision latitude, and workplace support were added as covariates, suggesting that these factors strongly influence the relationship between telework and work engagement. Determining the ideal intensity of telework may be difficult for workers during the COVID-19 pandemic, depending on their company's infection prevention measures. In this study conducted under a pandemic, the high-intensity teleworkers may not have had their choice to telework or come to the workplace. On the other hand, for low- and moderate-intensity teleworkers, the choice was available even under infection. Even though the analysis in this study was adjusted for decision latitude, this level of discretion regarding the choice of telework may have affected the results of this study. In particular, telework has been shown to reduce workplace support from supervisors and colleagues, so the implementation of support measures using Information and Communication Technology tools, such as web conferences, should be considered. 6,20

In the present study, workers with low- and moderate-intensity telework showed higher work engagement than those with no telework. Workers who are raising children spend more time engaged in housework than those without children, so the flexibility of time is important to these workers. ${ }^{12}$ However, telework makes switching between work time and personal time difficult. Stress responses experienced by individuals have been found to propagate across domains, from one area of life within an individual (eg, work) to another (eg, family life); this phenomenon is referred to as "spillover." 21 Previous studies have shown that working at home increases work stress, and work-family conflict mediates the effect. $^{22}$ Further, the degree of effect was stronger for women than for men. The present study did not take into account work-family conflict in its analysis, so further studies on this point are required. Studies in the United States have shown that home-based telework does not reduce work-family conflict and may actually increase working hours. ${ }^{23}$ Occupational health practitioners need to pay attention to this point when assessing the health impact of telecommuting on workers. 
TABLE 1. Demographic Characteristics, the Intensity of Home-Based Telework, and Work Engagement among Participants in this Study by Sex $(n=24,217)$

\begin{tabular}{|c|c|c|c|c|c|c|c|c|}
\hline & \multicolumn{4}{|c|}{ Men $(12,043)$} & \multicolumn{4}{|c|}{ Women $(12,174)$} \\
\hline & Mean & SD & $n$ & $\%$ & Mean & SD & $n$ & $\%$ \\
\hline Age (years) & 51.2 & 8.5 & & & 41.7 & 10.3 & & \\
\hline \multicolumn{9}{|l|}{ Education } \\
\hline Junior high school & & & 174 & 1.4 & & & 126 & 1.0 \\
\hline High school & & & 3,133 & 26.0 & & & 3,035 & 24.9 \\
\hline Junior college/technical school & & & 1,629 & 13.5 & & & 4,109 & 33.8 \\
\hline University & & & 6,166 & 51.2 & & & 4,485 & 36.8 \\
\hline Graduate school & & & 941 & 7.8 & & & 419 & 3.4 \\
\hline \multicolumn{9}{|l|}{ Yearly household income } \\
\hline$<2.50$ million JPY & & & 2,092 & 17.4 & & & 2,540 & 20.9 \\
\hline $2.50-3.75$ million JPY & & & 3,127 & 26.0 & & & 3,703 & 30.4 \\
\hline $3.75-5.25$ million JPY & & & 3,091 & 25.7 & & & 2,982 & 24.5 \\
\hline$>5.25$ million JPY & & & 3,733 & 31.0 & & & 2,949 & 24.2 \\
\hline \multicolumn{9}{|l|}{ Marriage } \\
\hline Married & & & 8,494 & 70.5 & & & 5,060 & 41.6 \\
\hline Divorced or bereaved & & & 781 & 6.5 & & & 1,708 & 14.0 \\
\hline Never married & & & 2,768 & 23.0 & & & 5,406 & 44.4 \\
\hline \multicolumn{9}{|l|}{ Presence of family living together } \\
\hline Present & & & 9,958 & 82.7 & & & 8,990 & 73.8 \\
\hline Absent & & & 2,085 & 17.3 & & & 3,184 & 26.2 \\
\hline \multicolumn{9}{|l|}{ Occupation } \\
\hline General employee & & & 5,720 & 47.5 & & & 6,855 & 56.3 \\
\hline Manager & & & 2,221 & 18.4 & & & 320 & 2.6 \\
\hline Executive manager & & & 709 & 5.9 & & & 153 & 1.3 \\
\hline $\begin{array}{l}\text { Public employee, faculty member, or non-profit } \\
\text { organization employee }\end{array}$ & & & 1,614 & 13.4 & & & 1,196 & 9.8 \\
\hline Temporary/contract employee & & & 1,030 & 8.6 & & & 1,864 & 15.3 \\
\hline $\begin{array}{l}\text { Professional occupation (lawyer, tax accountant, } \\
\text { medical-related, etc) }\end{array}$ & & & 479 & 4.0 & & & 1,368 & 11.2 \\
\hline Other occupation & & & 270 & 2.2 & & & 418 & 3.4 \\
\hline \multicolumn{9}{|l|}{ Category of industry } \\
\hline Energy, materials, and industrial machinery & & & 697 & 5.8 & & & 252 & 2.1 \\
\hline Food & & & 267 & 2.2 & & & 311 & 2.6 \\
\hline Beverages/tobacco products & & & 69 & 0.6 & & & 51 & 0.4 \\
\hline Pharmaceuticals/medical supplies & & & 198 & 1.6 & & & 194 & 1.6 \\
\hline Cosmetics/toiletries/sanitary products & & & 45 & 0.4 & & & 102 & 0.8 \\
\hline Fashion and accessories & & & 59 & 0.5 & & & 211 & 1.7 \\
\hline Precision machinery and office supplies & & & 288 & 2.4 & & & 169 & 1.4 \\
\hline Home appliances/audiovisual equipment & & & 317 & 2.6 & & & 146 & 1.2 \\
\hline Automobiles and transportation equipment & & & 561 & 4.7 & & & 307 & 2.5 \\
\hline Household goods & & & 30 & 0.2 & & & 32 & 0.3 \\
\hline Hobby/sporting goods & & & 28 & 0.2 & & & 23 & 0.2 \\
\hline Real estate and housing equipment & & & 406 & 3.4 & & & 354 & 2.9 \\
\hline Information and communication & & & 791 & 6.6 & & & 413 & 3.4 \\
\hline Distribution and retail & & & 747 & 6.2 & & & 738 & 6.1 \\
\hline Finance/insurance & & & 406 & 3.4 & & & 752 & 6.2 \\
\hline Transportation and leisure & & & 412 & 3.4 & & & 227 & 1.9 \\
\hline Restaurant and other services & & & 413 & 3.4 & & & 507 & 4.2 \\
\hline Public offices and organizations & & & 1,156 & 9.6 & & & 732 & 6.0 \\
\hline Education, medical services, religion & & & 1,208 & 10.0 & & & 3,045 & 25.0 \\
\hline Mass media & & & 111 & 0.9 & & & 87 & 0.7 \\
\hline Market research & & & 17 & 0.1 & & & 18 & 0.1 \\
\hline Other & & & 3,817 & 31.7 & & & 3,503 & 28.8 \\
\hline Psychological demands (JCQ) (range: 12-48) & 30.0 & 5.5 & & & 30.5 & 6.2 & & \\
\hline Decision latitude (JCQ) (range: 24-96) & 64.0 & 11.5 & & & 61.5 & 11.1 & & \\
\hline Workplace support (JCQ) (range: 8-32) & 20.6 & 4.8 & & & 20.7 & 5.0 & & \\
\hline \multicolumn{9}{|l|}{ Intensity of telework } \\
\hline High & & 1 & 907 & 7.5 & & & 775 & 6.4 \\
\hline Moderate & & 2 & 744 & 6.2 & & & 532 & 4.4 \\
\hline Low & & 3 & 842 & 7.0 & & & 521 & 4.3 \\
\hline No WAH & & 5 & 9,550 & 79.3 & & & 10,346 & 85.0 \\
\hline Work engagement (UWES-3) (range: 0-6) & 2.4 & 1.5 & & & 2.4 & 1.5 & & \\
\hline
\end{tabular}

JCQ, Job Content Questionnaire; JPY, Japanese Yen; UWES, Utrecht Work Engagement Scale. 


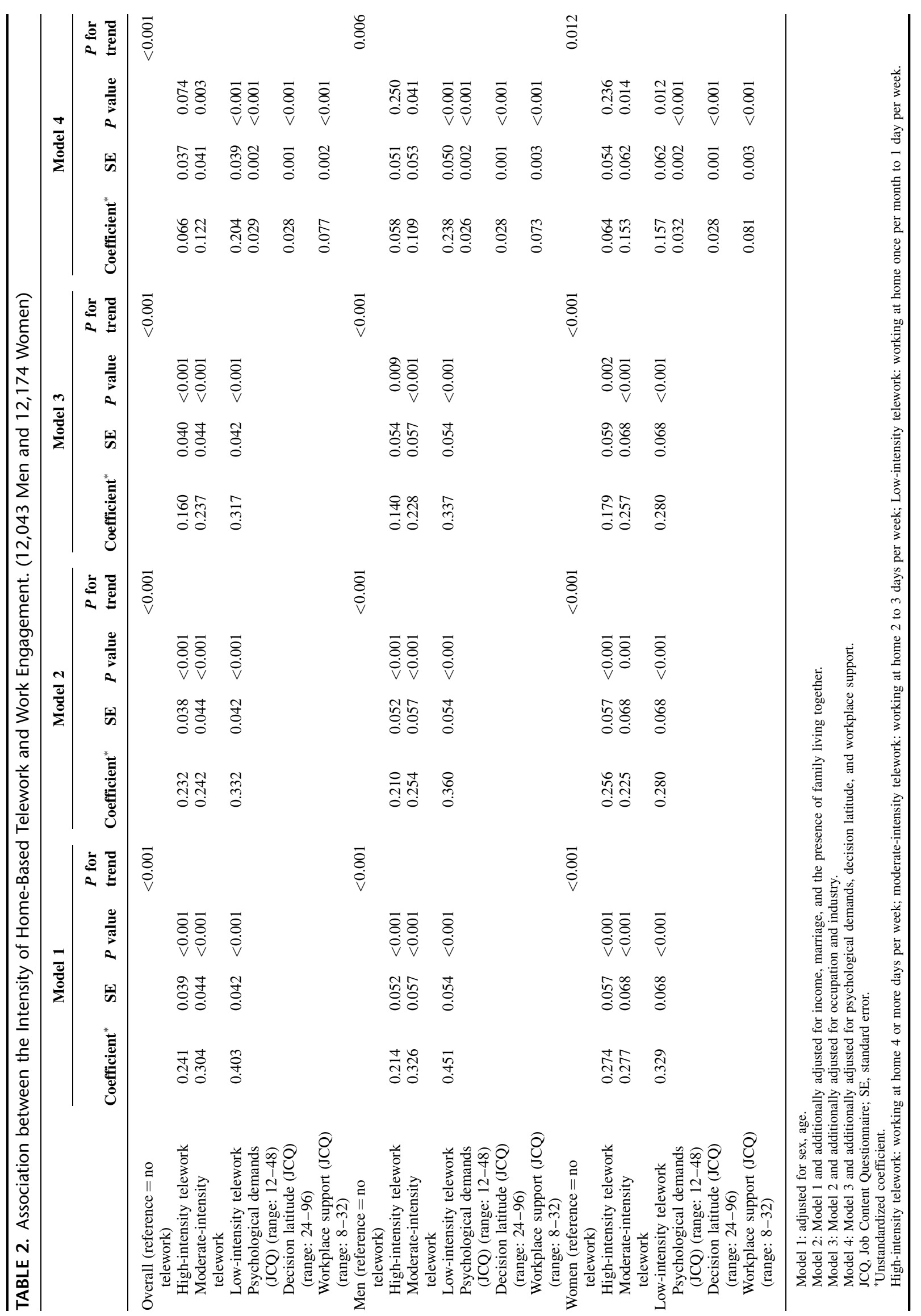


The present study is the first to show an association between the intensity of telework and work engagement under the COVID19 pandemic. However, several limitations associated with our study warrant mention. First, as the present study was conducted through the Internet, the extent to which the results may be generalized is unclear. However, to reduce bias as much as possible, we sampled the target population according to region, job type, and prefecture based on the infection incidence rate. Second, while work-family conflict may have influenced our findings, we did not enquire about such conflict in this study. However, we did adjust for marital status and the presence of family living together, which may have helped compensate for this lack of data. Third, because this was a cross-sectional study, the causal relationship between the intensity of telework and work engagement is unclear. Concerns have been raised about the existence of reverse causalities, such as not choosing telework because the task lowers work engagement. Research has been conducted to index the ease of telecommuting (feasibility of telework) based on job characteristics. ${ }^{24}$ In the present study, we adjusted for occupation and industry, which may have eliminated some of the effects of the feasibility of telework.

In conclusion, low- and moderate-intensity telework (once per month to 3 days per week) may have beneficial effects on work engagement. Certain factors associated with high-intensity telework (4 or more days per week) may not enhance work engagement; these factors should be clarified, and measures to increase work engagement should be taken.

\section{ACKNOWLEDGMENTS}

The present members of the Study Group are Dr Yoshihisa Fujino (present chairperson of the study group) and (in alphabetical order by given name) Dr Akira Ogami, Dr Arisa Harada, Dr Ayako Hino, Dr Chimed-Ochir Odgerel, Dr Hajime Ando, Dr Hisashi Eguchi, Dr Kazunori Ikegami, Dr Keiji Muramatsu, Dr Koji Mori, Dr Kyoko Kitagawa, Dr Masako Nagata, Dr Mayumi Tsuji, Ms Ning Liu, Dr Rie Tanaka, Dr Ryutaro Matsugaki, Dr Seiichiro Tateishi, Dr Shinya Matsuda, Dr Tomohiro Ishimaru, Dr Tomohisa Nagata, and Dr Yosuke Mafune. All members are affiliated with the University of Occupational and Environmental Health, Japan.

\section{REFERENCES}

1. Cabinet Secretariat, Japan. New corona infectious disease emergency declaration.Tokyo, Japan: Cabinet Secretariat, Japan. 2020. Available at: https:// corona.go.jp/news/pdf/kinkyujitai_sengen_0407.pdf. Published April 7, 2020. Accessed April 2, 2021.

2. Cabinet Secretariat, Japan. New corona infectious disease emergency declaration. Tokyo, Japan: Cabinet Secretariat, Japan. 2020. Available at: https:// corona.go.jp/news/pdf/kinkyujitaisengen_gaiyou0416.pdf. Published April 16, 2020. Accessed April 2, 2021.

3. PERSOL RESEARCH AND CONSULTING Co., Ltd. The Fourth Urgent Survey on the Impact of Countermeasures against a New Coronavirus on Telework. 2020

4. Tavares AL. Telework and health effects review. Int J Healthc. 2017;3: $30-36$.
5. Henke RM, Benevent R, Schulte P, Rinehart C, Crighton KA, Corcoran M The effects of telecommuting intensity on employee health. Am J Health Promot. 2016;30:604-612.

6. Vander Elst T, Verhoogen R, Sercu M, Van den Broeck A, Baillien E Godderis L. Not Extent of telecommuting, but job characteristics as proximal predictors of work-related well-being. J Occup Environ Med. 2017;59:e180e186.

7. Schaufeli WB, Salanova M, González-romá V, Bakker AB. The measurement of engagement and burnout: a two sample confirmatory factor analytic approach. J Happiness Stud. 2002;3:71-92.

8. Nagata T, Ito D, Nagata M, et al. Anticipated health effects and proposed countermeasures following the immediate introduction of telework in response to the spread of COVID-19: the findings of a rapid health impact assessment in Japan. J Occup Health. 2021;63:e12198.

9. Bouziri H, Smith DRM, Descatha A, Dab W, Jean K. Working from home in the time of COVID-19: how to best preserve occupational health? Occup Environ Med. 2020;77:509-510.

10. Hornung S, Glaser J. Home-based telecommuting and quality of life: further evidence on an employee-oriented human resource practice. Psychol Rep. 2009;104:395-402.

11. Oakman J, Kinsman N, Stuckey R, Graham M, Weale V. A rapid review of mental and physical health effects of working at home: how do we optimise health? BMC Public Health. 2020;20:1825.

12. Kim J, Henly JR, Golden LM, Lambert SJ. Workplace flexibility and worker well-being by gender. J Marriage Fam. 2020;82:892-910.

13. Kazekami S. Mechanisms to improve labor productivity by performing telework. Telecommun Policy. 2020;44:101868.

14. Fujino $\mathrm{Y}$, Ishimaru T, Eguchi $\mathrm{H}$, et al. Protocol for a nationwide Internetbased health survey in workers during the COVID-19 pandemic in 2020 . medRxiv. 2021. 2021.2002.2002.21249309.

15. Shimazu A, Schaufeli WB, Kosugi S, et al. Work engagement in Japan: validation of the Japanese version of the Utrecht Work Engagement Scale. Appl Psychol. 2008;57:510-523.

16. Schaufeli W, Shimazu A, Hakanen J, Salanova M, De Witte H. An ultra-short measure for work engagement: the UWES-3 validation across five countries. Eur J Psychol Assess. 2017;35:1-15.

17. Karasek R. Job Content Questionnaire and User's Guide. Lowell: University of Massachusetts at Lowell; 1985.

18. Kawakami N, Kobayashi F, Araki S, Haratani T, Furui H. Assessment of job stress dimensions based on the job demands- control model of employees of telecommunication and electric power companies in Japan: reliability and validity of the Japanese version of the Job Content Questionnaire. Int J Behav Med. 1995;2:358-375.

19. Ikegami $\mathrm{K}$, Baba $\mathrm{H}$, Ando $\mathrm{H}$, et al. Job stress among workers who telecommute under Coronavirus disease 2019 (COVID-19) pandemic in Japan: cross sectional study. medRxiv. 2021. doi: https://doi.org/10.1101/2021.03. 19.21253958 .

20. Bosua RGM, Kurnia S, Mendoza A, Yong J. Telework, productivity and wellbeing: an Australian perspective. Telecommun J Aust. 2013;63:11.11L11.12.

21. Bakker AB, Demerouti E. The Spillover-Crossover Model. New Frontiers in Work and Family Research. East Sussex, UK: Psychology Press; 2013.

22. Eddleston KA, Mulki J. Toward understanding remote workers' management of work-family boundaries: the complexity of workplace embeddedness. Group Organ Manag. 2015;42:346-387.

23. Noonan MC, Glass JL. The hard truth about telecommuting. Mon Labor Rev. 2012;38-45.

24. Dingel JI, Neiman B. How many jobs can be done at home? NBER Working Paper. 2020;26948. 